\title{
ANTIHYPERLIPIDEMIC PROPERTY OF BOERHAVIA DIFFUSA LEAF EXTRACT IN STREPTOZOTOCIN-INDUCED DIABETIC RATS
}

\author{
VASUNDHARA CCS ${ }^{1}$, GAYATHRI DEVI ${ }^{2 *}$ \\ ${ }^{1}$ Department of Biochemistry, Biotechnology and Bioinformatics, Avinashilingam Institute for Home Science and Higher Education for \\ Women, Coimbatore - 641 043, Tamil Nadu, India. ${ }^{2}$ Department of Biochemistry, Biotechnology and Bioinformatics, Avinashilingam \\ Institute for Home Science and Higher Education for Women, Coimbatore - 641 043, Tamil Nadu, India. Email: gayathridevi.adu@gmail.com \\ Received: 21 October 2017, Revised and Accepted: 30 December 2017
}

ABSTRACT

Objectives: The aim of the present research was to evaluate the antidiabetic, hyperlipidemic, and histopathological analysis in streptozotocin-induced diabetic rats (60 mg/kg body weight) using the ethanolic extract of leaves of Boerhavia diffusa (ELBD) (500 mg/kg body weight)

Method: The rats were orally administered with the leaf extract for 45 days. Fasting blood was collected at the end of the experimental period by cardiac puncture to carry out the biochemical parameters, the organs such as liver, kidney, and pancreas were also excised to perform the histopathological analysis by fixing in $10 \%$ formalin solution.

Results: Oral administration with the leaf extract resulted in decrease in the levels of blood glucose, with a concomitant increase in their body weight. The extracts also produced a significant decrease in the lipid levels when compared with the diabetic groups. Moreover, the extracts also exerted a favorable effect on the histopathological changes of liver, pancreas, and kidney.

Conclusion: The results of the present study revealed that the ELBD possess antidiabetic and antihyperlipidemic properties. These effects may be due to the presence of bioactive components justifying its ethnomedical use.

Keywords: Streptozotocin, Anti-inflammatory, Antidiabetic, Histopathological.

(C) 2018 The Authors. Published by Innovare Academic Sciences Pvt Ltd. This is an open access article under the CC BY license (http://creativecommons. org/licenses/by/4. 0/) DOI: http://dx.doi.org/10.22159/ajpcr.2018.v11i4.23226

\section{INTRODUCTION}

Diabetes mellitus is a complex disease that occurs when pancreas does not produce enough insulin or when the body cannot effectively utilize the insulin produced, resulting in hyperglycemia which may lead to a deleterious effect on $\beta$-cells. More than $80 \%$ of deaths due to diabetes occur in low- and middle-income countries. The World Health Organization (WHO) has projected that by the year 2030, diabetes will be the $7^{\text {th }}$ leading cause of death [1]. Medicinal plants have become popular to cure diseases because of its ease of availability, safety, and lesser side effect when compared to the currently available synthetic drugs [2]. Boerhavia diffusa (rakt punarnava) a prostrate growing herbaceous plant of Nyctaginaceae family has immense pharmaceutical significance. The plant is mainly used by herbalist, ayurvedic, and pharmaceutical industries for biopharmaceutical productions. The whole part of the plant has a numerous medicinal properties and has a long history of use by the tribal people in India and Unani medicine in Arab countries [3]. The present study was undertaken to investigate the antidiabetic effect of ethanolic extract of leaves of $B$. diffusa (ELBD) in streptozotocin (STZ)-induced diabetic rats.

\section{METHODS}

\section{Collection of plant material and extraction}

The experimental plant $B$. diffusa was collected from the areas in and around Coimbatore and duly authenticated from Botanical Survey of India, Coimbatore, with the authentication number BSI/ SRC/5/23/2013-14/Tech/1041. Fresh leaves (15 g) of B. diffusa were extracted by soaking in $95 \%$ ethanol in Soxhlet apparatus for $72 \mathrm{~h}$. The extract obtained was filtered and the solvent was removed using rotary evaporator apparatus and used for the study. Rats were given oral dose of the extract after 3 days of induction of diabetes.

\section{Chemicals}

Blood glucose, total cholesterol, triglycerides, high-density lipoprotein cholesterol (HDL-C) diagnostic kits, and STZ were obtained from Sigma, Chemico Co, USA. All the other chemicals and solvents used were of analytical grade.

\section{Experimental animals}

Male Wistar rats of 8-10 weeks old, weighing 150-200 g, were procured from KMCH College of Pharmacy, Coimbatore, India. The rats were acclimatized for a week under laboratory conditions. Animals were housed in polyethylene cages in an animal room maintained under standard environmental conditions such as ambient temperature $\left(25 \pm 2^{\circ} \mathrm{C}\right)$, relative humidity $50 \%-60 \%$, and $12 \mathrm{~h}$ light-dark cycle. They were fed with normal laboratory diet and water ad libitum. The animal experiments were carried out in accordance with the CPCSEA guidelines. The experimental animal protocol satisfied the guidelines for animal experimentation approved by the Institutional Animal Experimentation Committee (approval no: KU/IAEC/Ph.D/127/2013).

\section{Acute toxicity study}

Acute toxicity study was performed as per Organization for Economic Cooperation for Development 423 guidelines to find out the $\mathrm{LD}_{50}$. Male Wistar rats $(n=3)$ were used for acute toxicity study. The animals were kept fasting overnight having access to water only, after which the ELBD was administered orally at different doses of $(250,500,1000,2000$, and $5000 \mathrm{mg}$ ). The control animals received standard pellet diet and tap water. Mortality and general behavior of the animals were observed periodically for 48 hours and intermittently for the next 14 days.

\section{Induction of diabetes}

Diabetes mellitus was induced in the rats after $18 \mathrm{~h}$ fasting by single intraperitoneal injection of STZ at a dose of $60 \mathrm{mg} / \mathrm{kg}$ body weight in 
$0.01 \mathrm{M}$ sodium citrate buffer ( $\mathrm{pH} 4.5$ ). After 3 days, fasting blood glucose was measured and animals with blood glucose level $>200 \mathrm{mg} / \mathrm{dl}$ were used for the study.

\section{Experimental design}

The male Wistar rats were divided into four groups of six animals each. The grouping of the animals is as follows:

- Group I: Untreated control rats which received standard pellet diet and water throughout the experimental period.

- Group II: STZ-treated rats which served as diabetic control.

- Group III: Diabetic rats received ELBD (500 mg/kg body weight) orally for 45 days.

- Group IV: Diabetic rats which received known antidiabetic drug, glibenclamide (10 mg/kg body weight) orally for 45 days.

At the end of the study (after 45 days), the overnight fasting blood samples were collected by cardiac puncture and used for the biochemical analysis such as blood glucose [4], total cholesterol [5], triglyceride [6], HDL-C [5], and phospholipids [7]. The animals were later sacrificed by cervical dislocation to carry out the histopathological examination [8] in liver, heart, pancreas, and kidney by fixing in $10 \%$ formalin solution immediately after dissection.

\section{Statistical analysis}

Results were expressed as mean \pm standard deviation for six rats in each group. All the data were analyzed with SPSS student software. Statistical significance was determined by one-way analysis of variance. A value of $\mathrm{p}<0.05$ or less was considered statistically significant.

\section{RESULTS AND DISCUSSIONS}

\section{Acute toxicity study}

The acute toxicity study was conducted to determine the appropriate dosage which could be used for the subsequent experiment. The study reveals that the ELBD was non-toxic up to the highest dose of $5000 \mathrm{mg}$. During this study, there was no significant change in the behavior of the animals such as rearing, sniffing, grooming, locomotion, convulsion, eyeball movement, fur changes, and urination for $48 \mathrm{~h}$ after administration with the extract. The plant extract showed no toxic effect indicating that the minimal lethal dose $\left(\mathrm{LD}_{50}\right)$ may be $>5000 \mathrm{mg}$.

\section{Weight of the rats}

The effect of ELBD on the body weight of the rats was assessed at an interval of 7 days throughout the experimental period ( 45 days). The mean body weight of the control and experimental rats is represented in Fig. 1.

A significant reduction in the body weight of the diabetic rats induced with STZ was observed when compared to rats of the untreated control group. The control group recorded a significant weight gain compared to all the other groups during the treatment period. Oral administration with ELBD at the dose of $500 \mathrm{mg} / \mathrm{kg}$ body weight and standard drug glibenclamide at a dose of $10 \mathrm{mg} / \mathrm{kg}$ body weight showed a significant increase in their body weight when compared to diabetic control. Thus, proving that the ethanolic extract of $B$. diffusa and the standard drug glibenclamide has offered protection against diabetes mellitus.

The results of the present study were supported by the findings of Karki et al. [9] who have reported that the diabetic rats treated with the extracts of Zanthoxylum armatum registered a significant increase $(\mathrm{p}<0.001)$ in weight gain compared to the diabetic control rats. Similar results were also proved by Mohan et al. [10] who stated that the ethanolic leaf extract of Triticum aestivum significantly improved the body weight compared to the diabetic control group. Results of Gandhi and Sasikumar [11] have also confirmed that the plant extract Merremia emarginata showed a decrease in their body weight than that of the STZ-induced diabetic rats. The results of Divi et al. [12] revealed that the administration of aqueous extract of Moringa oleifera leaves completely prevented fructose-induced weight gain in insulin-resistant rats and partially prevented the weight loss observed in STZ-induced diabetic rats. Diabetes is associated with conditions such as elevated blood glucose, weight loss, nausea, numbness, polyuria, and polydipsia. In the present study, induction of diabetes by STZ caused a decrease in body weight, polyuria and increase in blood glucose and polydipsia which could be due to the metabolic changes caused by the lack or deficiency of insulin. The reduction in body weight of these diabetic rats might be due to the degradation of structural proteins caused due to the deficiency of carbohydrate metabolism. All these symptoms were rectified by the administration of ELBD and drug suggesting their hypoglycemic effect.

Effect on fasting blood glucose levels in STZ-induced diabetic rats Fig. 2 depicts the levels of blood glucose in normal and experimental rats on the $0^{\text {th }}, 3^{\text {rd }}, 7^{\text {th }}, 14^{\text {th }}, 21^{\text {st }}, 28^{\text {th }}$, and $45^{\text {th }}$ days.

The fasting blood glucose levels of diabetic rats were significantly higher than those of control rats. From the $3^{\text {rd }}$ day onward, the rats of all the groups showed an elevated blood glucose levels when compared to the rats in the control group. Diabetic rats treated with ELBD and glibenclamide registered a significant decrease in the levels of blood glucose on $14^{\text {th }}, 21^{\text {st }}, 28^{\text {th }}$, and $45^{\text {th }}$ days of treatment. STZ produces oxygen radicals in the body, which is considered to cause pancreatic injury and could be responsible for increased blood glucose observed in the diabetic rats. Thus, it can be inferred that the difference in the reduction of blood glucose observed between the treated groups might be dose dependent.

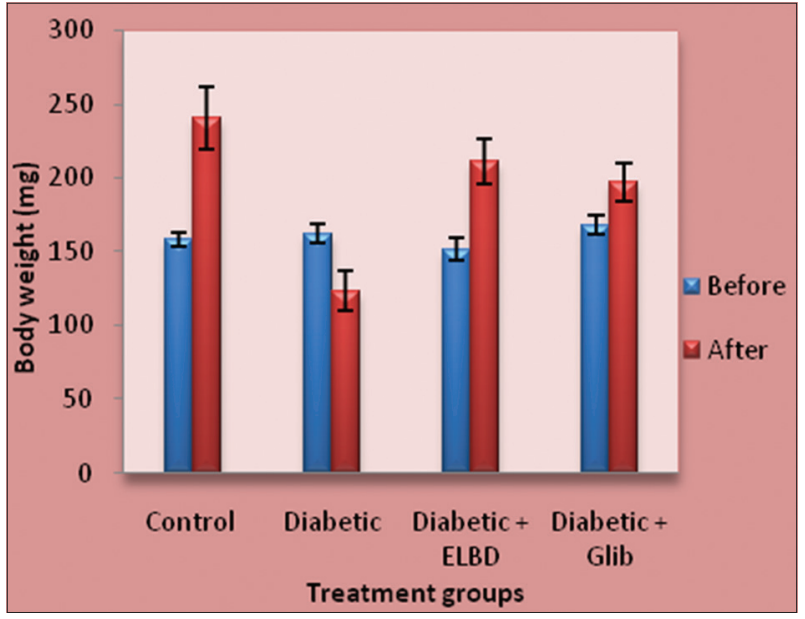

Fig. 1: Body weight of the rats. Values are mean \pm standard deviation ( $n=6$ rats in each group)

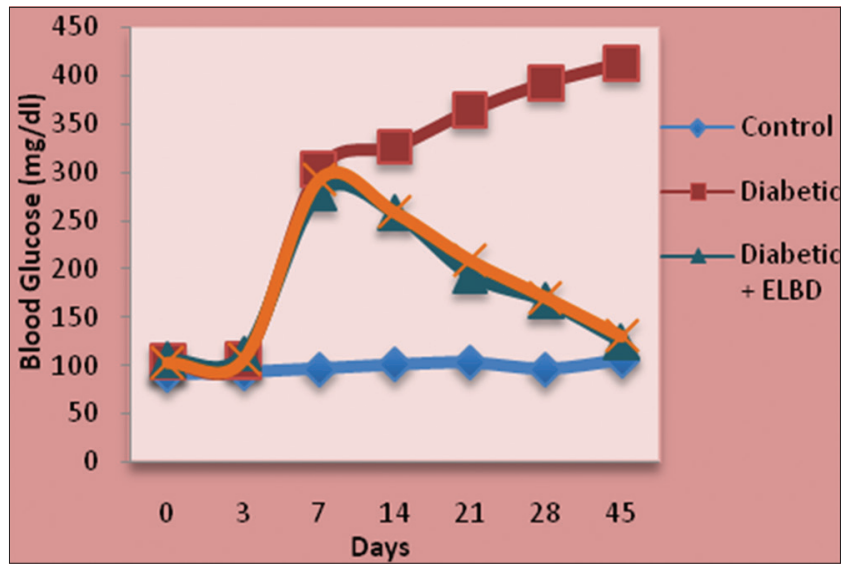

Fig. 2: Fasting blood glucose level in the experimental rats. Values are mean of $n=6$ rats in each group 
The experimental study of Kumar et al. [13] revealed that the administration of Paederia foetida leaf extract in the diabetic rats has restored the levels of blood glucose to near normal levels. Our results were similar to that of Dong et al. [14] who stated that the alcoholic Cordyceps militaris herb extract showed a decrease in the levels of fasting blood glucose in diabetic rats treated with extract than that of the control group. The results are also corroborative with that of Gandhimathi and Bai [15], who had reported a significant decrease of blood glucose $(\mathrm{p}<0.001)$ in the diabetic rats treated with ethanolic extract of Randia dumetorum (500 mg/kg b.w) when compared to the diabetic control rats. Hence, in the present study, administration with the ELBD and glibenclamide to the diabetic rats restored the levels of blood glucose to normal levels which may be due to the increased secretion of insulin from the existing beta-cells or from regenerated beta-cells proving the insulinogenic activity of the plant extract.

\section{Levels of lipid profile in experimental rats}

The effect of ELBD on serum lipid profile of the experimental rats was assessed and the results are presented in Table 1.

Table 1 summarizes the levels of cholesterol, triglycerides, HDL-C, low-density lipoprotein (LDL-C), very LDL cholesterol (VLDL-C), and phospholipids in the serum of experimental rats. A significant increase in the levels of serum cholesterol, triglycerides, VLDL-C, LDL-C, and phospholipids with a decrease in the levels of HDL-C in the STZ-induced diabetic rats was observed when compared with control rats.

Diabetic rats treated with ELBD and glibenclamide for 45 days registered a significant decrease in the levels of serum cholesterol, triglycerides, VLDL-C, LDL-C, and phospholipids with a concomitant increase in their HDL-C levels when compared with the diabetic rats. The activity of ELBD ( $500 \mathrm{mg} / \mathrm{kg}$ body weight)-treated diabetic rats was comparable with standard drug glibenclamide-treated diabetic rats and the control rats. This indicates that the treatment was effective in lowering the lipid levels (serum cholesterol, triglycerides, VLDL-C, LDL-C, and phospholipids) and improving the level of HDL-C in the rats.

Our results concurred with the earlier work done by Mishra et al. [16] who had reported a significant regulation in the lipid levels such as serum cholesterol, triglycerides, HDL-cholesterol, VLDL-cholesterol, and LDL-cholesterol, in the STZ-induced rats administered with the polyherbal formulation of aqueous extracts of Azadirachta indica, Camellia sinensis, and ethanol extract Asparagus racemosus. According to Soliman et al. [17], the data have revealed that diabetes induction caused a disturbance in lipid profile by a significant rise in the levels of total cholesterol, triglycerides, and LDL-C with a reduction in the HDL-C levels. Administration with the leaf extract of Petroselinum crispum to the diabetic rats decreased the levels of total cholesterol, triglycerides, and LDL with a simultaneous increase in the levels of HDL-C. The earlier studies of Subashini et al. [18] have also reported significant alterations in the lipid levels on STZ-induced diabetic rats treated with the methanolic extract of Gracilaria corticata. Insulin has a potent inhibitory effect on lipolysis in adipocytes; insulin deficiency is associated with excess lipolysis and influx of fatty acids to liver. The increased production of LDL-C and VLDL-C by the liver may be due to hepatic triglycerides synthesis as a result of influx of free fatty acids [15]. Administration with the ELBD to the experimental rats restored the lipid levels to normalcy.
During diabetes, profound alterations in the levels of lipid and lipoproteins are prone to greater risk of atherosclerosis and cardiovascular complications. Thus, the results suggest that the ELBD could play a protective role in restoring the diabetic complications by improving dyslipidemia.

\section{Histopathological analysis}

Histopathological studies of tissues (liver, pancreas, kidney, and heart) were undertaken and results are presented in Figs. 3-6.

Fig. 3 represents the histology of the normal liver section which shows well-arranged cells with clear central vein. In the diabetic group, the fatty changes in the hepatocytes are observed. The histopathological changes are restored to near normal in the ELBD- and glibenclamidetreated groups.

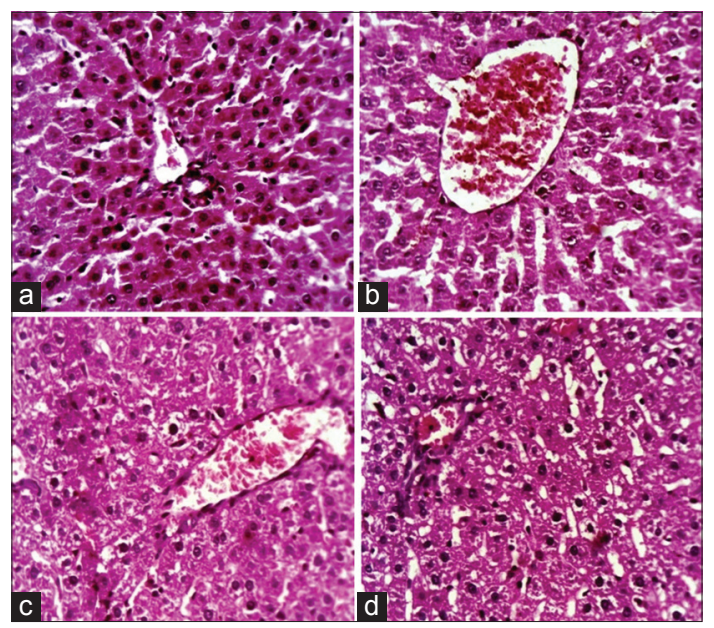

Fig. 3: Histopathological study of liver. (a) Control, (b) diabetic, (c) diabetic+ELBF, (d) diabetic+glibenclamide

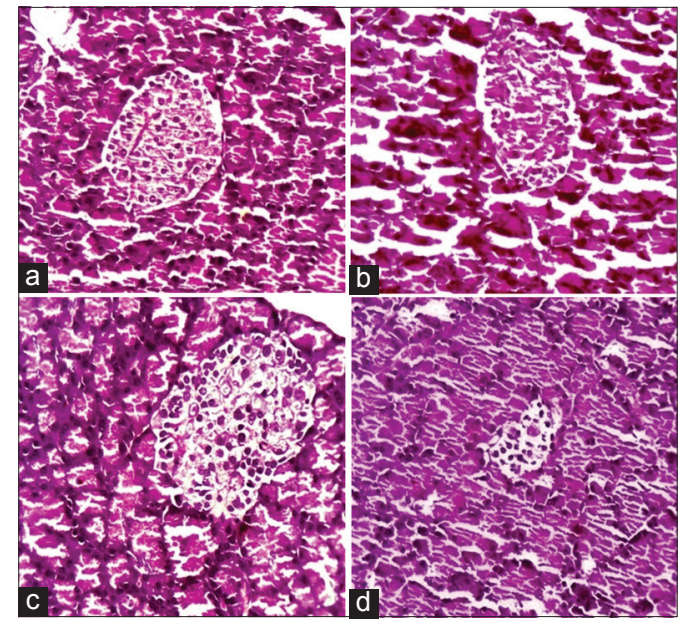

Fig. 4: Histopathological study of pancreas. (a) Control, (b) diabetic, (c) diabetic+ELBF, (d) diabetic+glibenclamide

Table 1: Serum lipid profile levels

\begin{tabular}{|c|c|c|c|c|c|c|}
\hline Groups & $\begin{array}{l}\text { Total cholesterol } \\
(\mathrm{mg} / \mathrm{dl})\end{array}$ & $\begin{array}{l}\text { Triglycerides } \\
(\mathrm{mg} / \mathrm{dl})\end{array}$ & $\begin{array}{l}\text { HDL-C } \\
\text { (mg/dl) }\end{array}$ & $\begin{array}{l}\text { LDL-C } \\
(\mathrm{mg} / \mathrm{dl})\end{array}$ & $\begin{array}{l}\text { VLDL-C } \\
\text { (mg/dl) }\end{array}$ & $\begin{array}{l}\text { Phospholipids } \\
\text { (mg/dl) }\end{array}$ \\
\hline Control & $84.00 \pm 3.61$ & $68.04 \pm 3.08$ & $40.64 \pm 1.80$ & $29.71 \pm 2.30$ & $13.61 \pm 1.93$ & $171.90 \pm 4.13$ \\
\hline Diabetic & $157.33 \pm 2.52$ & $119.00 \pm 6.82$ & $26.00 \pm 9.66$ & $107.52 \pm 6.82$ & $23.80 \pm 1.90$ & $269.70 \pm 5.55$ \\
\hline Diabetic+ELBD & $92.33 \pm 4.04$ & $77.27 \pm 4.19$ & $38.32 \pm 3.03$ & $38.55 \pm 3.06$ & $15.45 \pm 2.09$ & $193.90 \pm 3.26$ \\
\hline Diabetic+Glibenclamide & $93.66 \pm 3.51$ & $75.11 \pm 4.49$ & $37.00 \pm 3.26$ & $41.65 \pm 1.94$ & $15.02 \pm 3.06$ & $195.80 \pm 3.79$ \\
\hline$C D(0.05)$ & 6.52 & 9.12 & 10.15 & 7.59 & 4.32 & 8.04 \\
\hline
\end{tabular}

Values are mean \pm SD ( $n=6$ rats in each group). HDL-C: High-density lipoprotein, LDL-C: Low-density lipoprotein, VLDL-C: Very low-density lipoprotein 


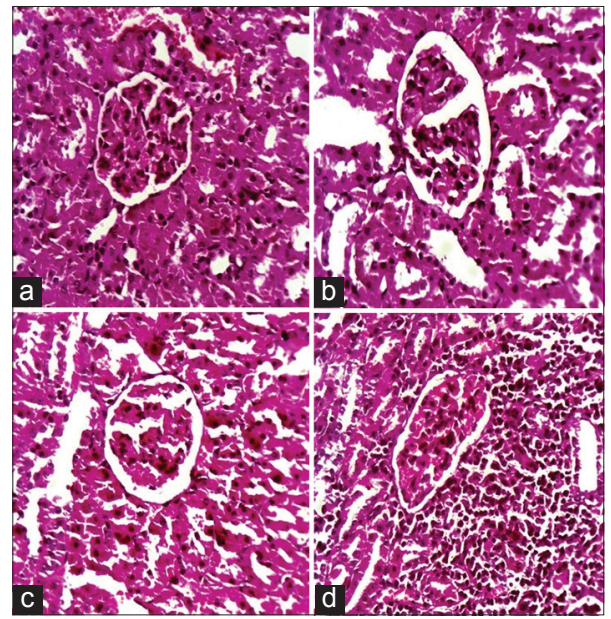

Fig. 5: Histopathological study of kidney. (a) Control, (b) diabetic, (c) diabetic+ELBF, (d) diabetic+glibenclamide

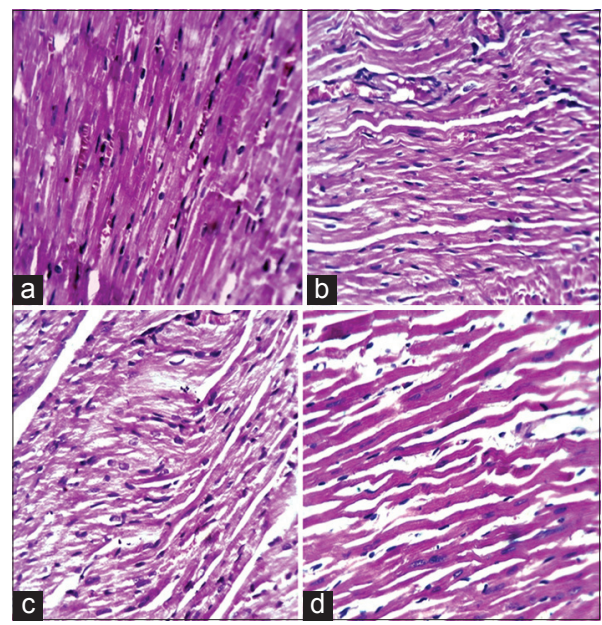

Fig. 6: Histopathological study of heart. (a) Control, (b) diabetic, (c) diabetic+ELBF, (d) diabetic+glibenclamide

The kidney section (Fig. 4) of normal group shows well-arranged cells. Diabetic group shows glomerulosclerosis along with focal interstitial inflammations. Reduction in focal interstitial inflammations is observed on treatment with ELBD and glibenclamide.

The pancreatic section (Fig. 5) shows well-arranged cells with normal islets of Langerhans in the control. The diabetic group showed a decrease in the number and size of islets of Langerhans. The number and the size of islets of Langerhans are restored to normal in diabetic rats treated with ELBD and glibenclamide.

Fig. 6 shows the normal architecture of the cardiac muscle fibers. There is no evidence of fatty change, myocardial necrosis or infarction in all the groups. Hence, it could be concluded that ELBD was non-toxic and regenerated the toxic effect of STZ.

Our results were similar to that of Oche et al. [19] who reported that the administration of ethanolic leaf extract of Vitex doniana in the diabetic rats revealed restoration of size of the islets along with $\beta$-cells repair when compared to that of non-diabetic rats which showed sinusoidal spaces with few scattered areas. The experimental evidences given by Latha et al. [20] confirm the significant recovery of liver and kidney destruction in the diabetic rats treated with the plant extract of Caralluma fimbriata.

\section{CONCLUSION}

The results of the present study prove that the ELBD has exhibited a synergistic action on the levels of blood glucose and lipid profile which may be due to the restoration of the pancreatic cells in the STZ-treated rats. Moreover, antidiabetic and antihyperlipidemic property of the leaf extract is also evidenced by the histopathological examination of liver, pancreas, kidney, and heart. Further, investigations are needed to prove the ethnomedicinal properties of the extract.

\section{REFERENCES}

1. Kenneth M, Molecules to Medicine with mTOR: Translating Critical Pathways into Novel Therapeutic Strategies. London: Academic Press; 2016.

2. Gavamukulya Y, Abou-Elella F, Wamunyokoli F, AEl-Shemy H. Phytochemical screening, anti-oxidant activity and in vitro anticancer potential of ethanolic and water leaves extracts of Annona muricata (Graviola). Asian Pac J Trop Med 2014;7S1:S355-63.

3. Patil KS, Bhalsing SR. Efficient micropropagation and assessment of genetic fidelity of Boerhaavia diffusa L- High trade medicinal plant. Physiol Mol Biol Plants 2015;21:425-32.

4. Hjelm M, de Verdier CH. A methodological study of the enzymatic determination of glucose in blood. Scand $\mathrm{J}$ Clin Lab Invest $1963 ; 15: 415-28$.

5. Allain CC, Poon LS, Chan CS, Richmond W, Fu PC. Enzymatic determination of total serum cholesterol. Clin Chem 1974;20:470-5.

6. Van Handel E, Zilversmit DB, Micromethod for the direct determination of serum triglycerides, Journal of Laboratory and Clinical Medicine 1957;50:152-7.

7. Zilversmit DB, Davis AK. Microdetermination of phospholipids by TCA precipitation. J Lab Clin Med 1950;35:155-9.

8. Culling CF. Handbook of Histopathological and Histochemical Techniques. $3^{\text {rd }}$ ed. New York: Butterworth and Co. Ltd.; 1979. p. 7.

9. Karki H, Upadhayay K, Pal H, Singh R. Antidiabetic potential of Zanthoxylum armatum bark extract on streptozotocin-induced diabetic rats. Int J Green Pharm 2014;8:77-83.

10. Mohan Y, Jesuthankaraj GN, Ramasamy Thangavelu N. Antidiabetic and antioxidant properties of Triticum aestivum in streptozotocininduced diabetic rats. Adv Pharmacol Sci 2013;2013:716073.

11. Gandhi GR, Sasikumar P. Antidiabetic effect of Merremia emarginata burm. F. In streptozotocin induced diabetic rats. Asian Pac J Trop Biomed 2012;2:281-6.

12. Divi SM, Bellamkonda R, Dasireddy SK. Evaluation of antidiabetic and antihyperlipedemic potential of aqueous extract of Moringa oleifera in fructose fed insulin resistant and stz induced diabetic Wistar rats: A comparative study. Asian J Pharm Clin Res 2012;5:67-72.

13. Kumar V, Anwar F, Ahmed D, Verma A, Ahmed A, Damanhouri ZA, et al. Paederia foetida linn. Leaf extract: An antihyperlipidemic, antihyperglycaemic and antioxidant activity. BMC Complement Altern Med 2014;14:76.

14. Dong Y, Jing T, Meng Q, Liu C, Hu S, Ma Y, et al. Studies on the antidiabetic activities of Cordyceps militaris extract in dietstreptozotocin-induced diabetic sprague-dawley rats. Biomed Res Int 2014;1-11

15. Gandhimathi S, Bai GV. Antidiabetic activity of Randia dumetorum against streptozotocin (STZ) induced diabetics in rats. Int J Pharm Res 2014;4:126-9

16. Mishra J, Dash AK, Dash DK, Hypoglycemic, hypolipidemic and antioxidant potentials of specially formulate polyherbal, formulation in streptozotocin induced diabetic rats. Eur Sci J 2014;10:340-51.

17. Soliman HA, Eltablawy NA, Hamed MS. The ameliorative effect of Petroselinum crispum (Parsley) on some diabetes complications. J Med Plants Stud 2015;3:92-100.

18. Subashini S, Kripa KG, Pugalendi KV. Hypolipidemic potential of methanolic extract of Gracilaria corticata on streptozotocin-induced diabetic rats. Asian J Pharm Clin Res 2017;10:402-5.

19. Oche O, Sani I, Chilaka NG, Samuel NU, Samuel A. Pancreatic islet regeneration and some liver biochemical parameters of leaf extracts of Vitex doniana in normal and streptozotocin-induced diabetic albino rats. Asian Pac J Trop Biomed 2014;4:124-30.

20. Latha S, Rajaram K, Kumar PS. Hepatoprotective and antidiabetic effect of methanolic extract of Caralluma fimbriata in streptozotocin induced diabetic Albino rats. Int J Pharm Pharm Sci 2014;6:665-8. 